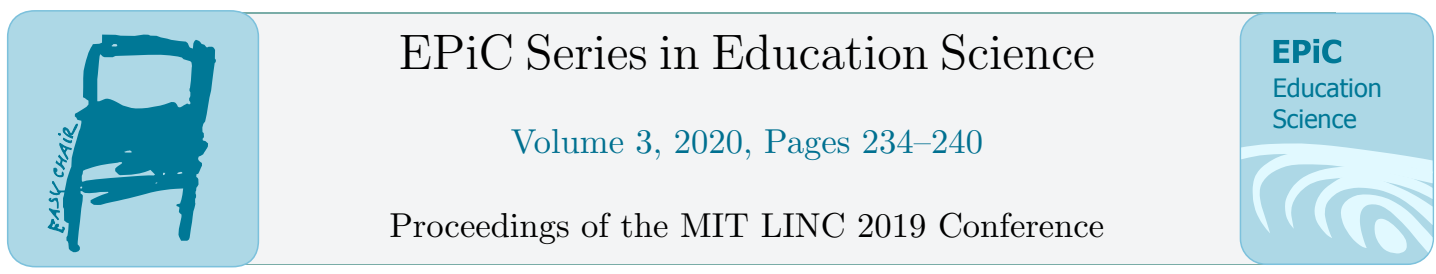

\title{
The Effects of Interactive Whiteboard on the Academic Performance of Deaf Students in Federal College of Education (Special), Oyo, Nigeria
}

\author{
Sunday Ayodele Taiwo ${ }^{1}$ and Ogunpeju Adefunke Taiwo ${ }^{1}$ \\ ${ }^{1}$ Federal College of Education (Special), Oyo, Nigeria \\ sunayotaiwo@yahoo.com, taiwopeju43@yahoo.com
}

\begin{abstract}
As interactive whiteboard (IWB) becomes more popular, teacher educators and students are expected to teach and learn using interactive whiteboard: This study was conducted at the Federal College of Education (Special), Oyo during first semester of 2017/2018 academic session in order to determine the effects of IWB on the academic performance of the deaf and hard of learning students who attended "Educational Technology: Theory and Practice" course. The finding gained in this research showed that a significant difference in favour of the IWB class versus the conventional class in the posttest. In the IWB class, IWB system was used. Therefore, it was seen that the use of IWB system increased the student achievement effectively.
\end{abstract}

\section{$1 \quad$ Introduction}

The learning problems of deaf students cannot be described only in terms of their degree of hearing. Factors such as language acquisition and the ability to interact with the social world are part of this complex communication handicap. Deaf and hearing impaired individuals have trouble translating oral communication into their inner language system. As a result, a great deal of information conveyed to them by the hearing world, either in the form of print or oral communication, is often lost or misinterpreted by them. They have not had the variety of auditory stimulus to which the hearing person is exposed (Hagen, 1984). This influences their classroom performances negatively, and it deprives them ability to compete favourably with their counterparts in classroom especially in mainstream college.

The students' hearing losses were what were hindering their abilities to be successful in the conventional classroom. Study shows that students' hearing loss may no longer be the only obstacle they may need to overcome. According to the Gallaudet Research Institute (GRI), it is estimated that approximately $39 \%$ of children who are deaf or hard of hearing have an additional disability (GRI, 2011). Of those $39 \%$ of children with additional disabilities, $13.4 \%$ of children have other learning disabilities (GRI, 2011). According to (Soukup \& Feinstein, 2007) a child who is deaf or hard of hearing is more likely to have a learning disability than a child with typical hearing (Soukup \& Feinstein, 2007). These additional learning disabilities include Attention Deficit Disorder (ADD), Attention Deficit Hyperactivity Disorder (ADHD), and other specific learning disabilities. These other signs of a possible learning disability are difficulty in achieving at the level of their peers, inconsistent performance in school, discrepancy between achievement and potential (Soukup \& Feinstein,2007). 
As a result of the advancement in communication and network technologies, more innovative instructional delivery and learning solutions have emerged in order to provide meaningful learning experiences for deaf and hard of hearing learners in academic settings. Interactive whiteboard is one of the various methods being used to deliver meaningful learning experiences. Interactive whiteboard (IWB) has become popular in the last ten years, throughout the world because of its potential to facilitate and improve learning.

An IWB is a large, touch, sensitive display panel that can function as an ordinary whiteboard, a projector screen, an electronic copy board or as a computer projector screen on which the computer image can be controlled by touching the surface of the panel instead of using a mouse or keyboard (Kennewell \& Morgan, 2003). The technology allows the user to write or draw on the surface, print the image off, save it to computer or distribute it over a network. The user can also project a computer screen image onto the surface and then control the application either by touching the board directly or by using a special pen. The computer image can be annotated or drawn over, and the annotations saved (Kennewell \& Morgan, 2003).

The board can accommodate different learning styles. Tactile learners can benefit from touching and marking at the board, audio learners can have the class discussion; visual learners can see what is taking place as it develops at the board. Students with limited motor skills can enjoy board use. Because of large format, it may be easier for students to run programs by tapping on the board rather than mouse clicking. Also, teachers with young students report success having them write on the board with their fingers rather than the stylus.

Moreover, the efficacy of IWB as an attention gaining device has been well document. (Beauchamp \& Allen, 2012; Radmacher \& Ryle, 2014). Zuck \& Nelson (2010) found out that attention was more sustained when IWB was incorporated in teaching-learning process. BECTA (2004) suggests that amongst other benefits, IWB enables and enhances presentation of content, allows students to absorb information more easily and to participate in classroom discussions by freeing them from copious note taking and saves teachers valuable preparation time.

In a comparison of two groups of students who completed a course in IWB class and conventional class, (Adamu \& Bassong, 2016) found that IWB class was more effective than classroom instruction as final examination on the course revealed that IWB group outperformed their conventional classroom counterparts. But, in another investigation of time spent to complete a task, Joseph-Beak, (2015).found IWB learning requires more time than conventional classroom learning. In a comparison of IWB learning and conventional classroom in college of Education, Rajas (2011) found that IWB learning courses enable students to more effectively understand course content. He attributes the significance of IWB learning to better interactive learning environment, increased learning resources, and convenience. Based on this background this study investigated the effects of IWB on the academic performance of deaf students in Federal College of Education (Special), Oyo, Nigeria. Therefore, the following hypotheses guided the study:

i. There is a significant difference between the average of pre test and post tests of the conventional group.

ii. There is a significant difference between the average of pre test and post tests of the IWB group.

iii. There is a significant difference between the averages of post tests of the IWB and conventional groups.

\section{Method}

This paper reports findings of a study that examined the comparison of deaf students' performance in a IWB class and conventional classroom setting. Two groups of students enrolled in classroom and IWB sections of the same course, were compared. In the IWB class, a computer, a projector, appropriate software, and a display panel were used as the medium of instruction. 
The students were 95 deaf enrolled in an educational technology course - EDU 212 that all college of education students are required to complete. The course content covered: the concept and history of educational technology in Nigeria, the place of educational technology in communication and the teaching-learning processes at the Junior Secondary Level, the concept and process of communication, the concept of systems approach to instruction (SAI) at the Junior Secondary Level, Multi-Media in Junior Secondary Education, Major characteristics of educational media; use of multi-media in promoting Interdisciplinary/integrated studies, computer-assisted teaching/learning at the Junior Secondary Level and photocopy and video production (with practical),

The IWB group engaged in activities in and outside the classroom such as drag and drop item; import existing graphics (clip arts, pictures, etc); save and open files; incorporate video files into lesson; matching items,; use of mouse to control activities; imported use of scanned images; annotating important content; use of hypertext and hyperlinks within and between programme; using visual keyboard and flipping back and forth content.

The course also required students to submit a practical project, and complete a final exam. The two researchers taught the two groups, IWB class and conventional class. At the beginning of the semester, the researchers introduced the course and discussed with students course requirements and expectation, and student completed a pretest assessment. In the middle of the semester, the class met to discuss progress and experiences during the previous eight weeks. During the last two weeks of the semester, there was a classroom meeting to complete course evaluation. Students also completed a post test assessment and submitted their practical projects.

In this study "conventional classroom is used to describe traditional face-to-face classroom setting. The researchers ensured that the IWB and conventional classes progressed simultaneously. For example, the same topics were scheduled for both classes each week, although delivery format differed.

The IWB class and convention class were selected by using cluster analysis in order to maintain objectivity between the students. The cluster analysis criteria were: the GPA which the students achieved in the $1^{\text {st }}$ and $2^{\text {nd }}$ semesters of their 100 level, and the result points that the student achieved in the pretest.

\section{Instrument}

The instrument developed for this study was guided by reviewing past literature and experts' views. The instrument is a 100 multi choice test comprising of two sections as follows:

1. The first: participants' demographic background.

2. The second section: 100 multi choice test spread across course content.

In terms of reliability, cronbach's alpha reliability value for the instrument was 0.88 . For the content validity of the instrument, the support of the lecturers in the School of Education and School of Special Education of the Federal College of education (Special) Oyo were sought and the lecturers responded positively.

\section{Data Analysis}

For the related analysis of the individual characteristics and test results of the students, frequency, percentage mean and standard deviation were used. However, in the analysis of the obtained data and in the comparison of the score from the pre-test and post-test, dependent and independent groups $t$ tests were used.

\section{Results}

Ninety five deaf students completed the pretest and posttest at the beginning and at the end of the semester in the two classes. The data on sex, age and course of study are presented in table 1. 


\begin{tabular}{|l|c|c|}
\hline \multicolumn{1}{|c|}{ Variable } & N & \% \\
\hline Age & 15 & 15.8 \\
\hline$<20$ & 72 & 75.8 \\
\hline $21-29$ & 08 & 8.4 \\
\hline $30-39$ & 0 & 0 \\
\hline$>40$ & & \\
\hline Sex & 39 & 41.1 \\
\hline Male & 56 & 58.9 \\
\hline Female & & \\
\hline Course of Study and & 19 & 20 \\
\hline Science & 21 & 22.1 \\
\hline $\begin{array}{l}\text { Vocational } \\
\text { Technical }\end{array}$ & 32 & 33.6 \\
\hline Arts and Soc. Science & 25 & 26.3 \\
\hline Languages & & \\
\hline
\end{tabular}

Table 1:- Student Demographics (Sex, Age and course of study)

\begin{tabular}{|l|cc|c|c|c|}
\hline \multicolumn{1}{|c|}{ Groups } & \multicolumn{2}{|c|}{ Range } & Mean & $\begin{array}{c}\text { Standard } \\
\text { Deviation }\end{array}$ & t \\
\hline IWB class & 38 & & 16.58 & 5.64 & \multirow{2}{*}{$-0.52 *$} \\
\hline Conventional class & 57 & 15.36 & 4.31 & \\
\hline
\end{tabular}

Table 2:- The Pre Test result points applied to the IWB and conventional classes and their comparison

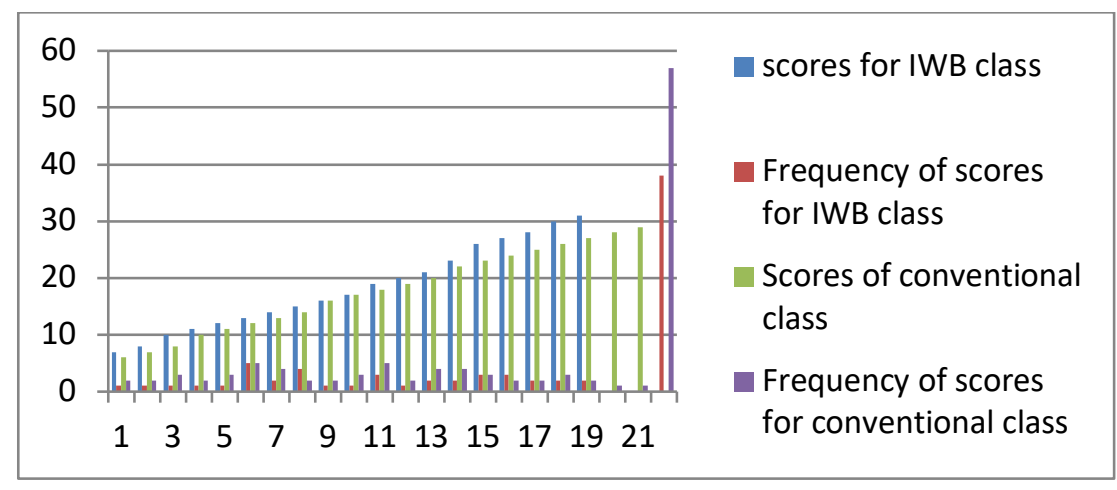

Figure 1: Pre-test scores and frequencies for IWB and Conventional classes.

Table 2 shows that there have been no significant differences between the IWB class and the conventional class in the results of the pre-test. Since both classes had low scores in the pretests, there had been no significant difference between their knowledge of the subject prior to starting the course.

\begin{tabular}{|c|c|c|c|c|}
\hline Test Type & Range & Mean & $\begin{array}{l}\text { Standard } \\
\text { Deviation }\end{array}$ & $\mathbf{t}$ \\
\hline Pre-test & 57 & 16.54 & 5.43 & \\
\hline Post-test & 57 & 31.72 & 5.74 & $-15.38^{*}$ \\
\hline
\end{tabular}

Table 3:- Pre-test and post-test results of the conventional class and their comparisons. 


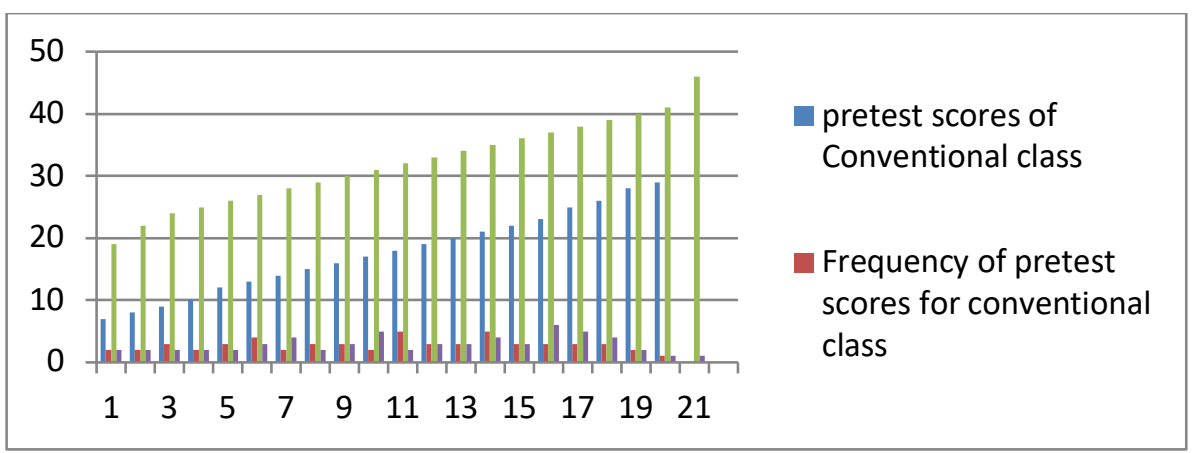

Figure 2: The Pre-test and post-test scores and frequencies for the conventional class

The results of the groups in the pretest and posttest had been compared with the t-test results of the dependent groups. For these comparisons, the dependent groups' t-test was used. The difference between the post-test and pre-test of the conventional class was significant (see Table 3) This result has confirmed the first hypothesis of the study stating. "There is a significant difference between the averages of pre-test and post-test results of the conventional class".

\begin{tabular}{|l|c|c|c|c|}
\hline Test Type & Range & Mean & Standard Deviation & T \\
\hline Pre-test & 38 & 17.43 & 6.31 & \multirow{2}{*}{$-18.65^{*}$} \\
\hline Post-test & 38 & 38.11 & 4.52 & $* \mathrm{P}<.05$ \\
\hline
\end{tabular}

Table 4:- Pre-test and post-test results of the IWB class and their comparisons.

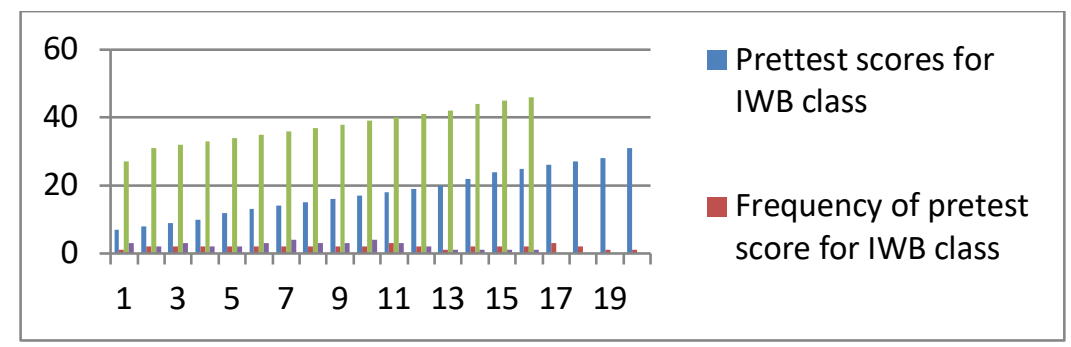

Figure 3: Pre-test and post-test scores and frequencies for IWB class

Table 4 shows the findings related with the second hypothesis of the study which states that "There is a significant difference between the averages of pre-test and post-test of the IWB class. It shows that there is a significant difference between the averages of pre-test and post-test results of the IWB class. 


\begin{tabular}{|l|c|c|c|c|}
\hline \multicolumn{1}{|c|}{ Group } & Range & Mean & $\begin{array}{c}\text { Standard } \\
\text { Deviation }\end{array}$ & t \\
\hline Conventional & 57 & 31.72 & 5.75 & \multirow{2}{*}{$-5.39 *$} \\
\hline IWB & 38 & 38.11 & 4.71 & \\
\hline & \multicolumn{4}{|c}{$* \mathrm{P}<.05$} \\
\hline
\end{tabular}

Table 5:- The post-test results of the IWB and conventional classes and their comparisons.

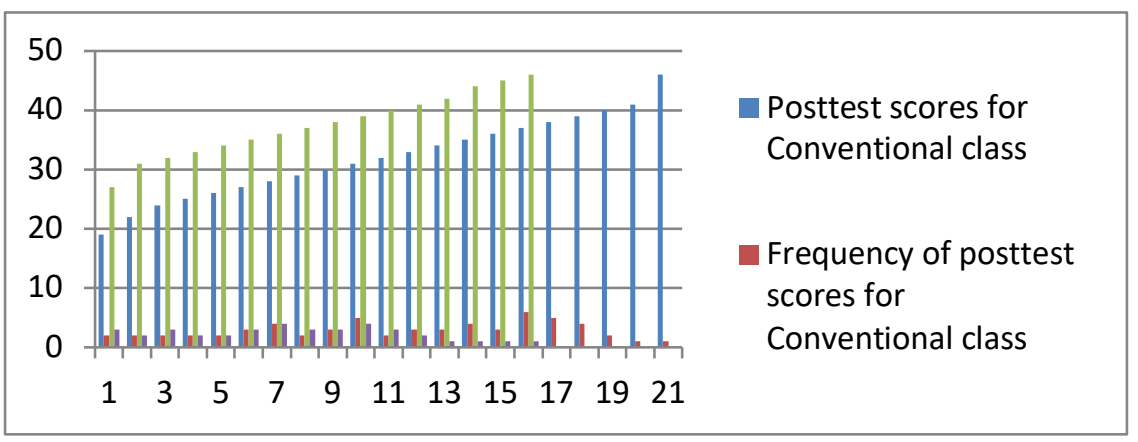

Figure 4: The post-test scores and frequencies for IWB and Conventional classes

The third hypothesis is related with the difference of the final test results of IWB and conventional classes and this difference is shown in Table 5. This comparison was performed with the independent groups' t-test. There was a significant difference between the post test results in favour of the IWB class. This result clearly shows the positive effect of IWB on the academic performance of deaf students.

\section{Discussion}

Analysis of academic performance test indicates there was no significant difference between the results of the IWB and conventional classes as regards pre-test. The implication of this result was that the two classes were of the same academic achievement level before the treatment.

In the conventional class, the lectures were conducted with traditional talk and chalk methods, and this caused a significant difference between the pretest and post-test results in favour of the post-test. In the IWB class, the lectures were conducted with interactive white boards, and this caused a significant difference between the pre test and post test results in favour of the post test. Similarly the difference was significantly higher than the one with the conventional class.

There was a significant statistical difference between the results of academic performance test applied to the IWB and conventional classes as a post-test in favour of the IWB class. An important feature distinguishing the IWB class was that students were able to spend over double the time on their own in using the board than was possible in the conventional class. This study provides an additional insight into prior research conducted in IWB and conventional learning. The findings reveal that learning environment and the instructional medium have impact on student learning.

Studies examining the effect of IWB on learning need to account for such variables as competency building requirements in the use of IWB and how such variables may affect outcome. Future research should look into that area. The study has limitation because the data was collected from a sample drawn from one college out of over 100 colleges of education in Nigeria, the findings may have limited generalizability. 
The results of this study have implications for Special Educators and policy makers on education for special need people. Assistive Technology should be incorporated into the curriculum at all levels of education for special people so as to enable them to benefit immensely from teaching-learning process.

\section{References}

Adamu, A. and Bassong, K. (2016). Study of comparison of two groups of students who completed a course in IWB class and conventional class". Journal of contemporary education. 22(4); (pp. 8-17).

Beauchamp, P and Allen, P (2012). A Study of Attention Span of Deaf Students in Higher Institution. Continental Journal of Deaf Education. 42(1), (pp. 151-182)

British Educational Communication and Technology Agency, BECTA. (2004) "Getting the most from your interactive whiteboard". A guide for secondary schools. Conventry.

Gallaudet Research Institute. (GRI) (April, 2011). Regional and National Summary Report of Data from the 2009-2010. Annual Survey of Deaf or hard of hearing Children and Youth. 2009-2010.

Hagen, E.J. (1984). New dimensions in deaf education. Nairobi: Macmillan

Joseph-Beak, K. (2015). Secondary student's use of IWB at school. Journal of Science and Technology. 52(3); (pp. 84-96).

Kennewell, S and Morgan, A. (2003). Student Teachers' Experiences and Attitudes Towards Using Interactive Whiteboards in the Teaching and Learning of Young Children. Proceedings of Young Children and Learning Technologies Conference. Sydney; International Federation for Information Processing.

Radmacher, S and Ryle, G. (2014). Effect of Technology on Academic Performance of mainstream Deaf Students in Mathematics. Studies in Disability. 14(4); (pp. 18-31).

Rajas. T.A. (2011). Learning of with IWB at primary level: Students' perceptions, Journal of Education and Technology. 17(2); (pp. 37-48).

Soukup, M and Feinstein, S (2007). Identification, Assessment and Intervention Strategies for Deaf or hard of hearing Students with Learning Disabilities. American Annals of the Deaf, 152, (pp. 5662). Company

Zuck, A and Nelson, M. (2010). Attention Deficits and hearing Loss. Auckland: Nelson Publishing 